\title{
Characterization of $\mathrm{WO}_{3}$ layers deposited on Quartz and Lithium Niobate SAW resonators for the design of gas sensors
}

\author{
M. David, M. Arab, J.R. Gavarri \\ Université du Sud Toulon Var \\ IM2NP UMR CNRS 6242 \\ La Garde, France \\ marjorie.david@univ-tln.fr
}

\author{
D. Rabus ${ }^{1}$, W. Daniau ${ }^{1}$, T. Baron ${ }^{1}$, J.M. Friedt ${ }^{*}$, L. \\ Delmas ${ }^{*}, \mathrm{~S}$. Ballandras ${ }^{1 *}$ \\ ${ }^{1}$ FEMTO-ST, UMR 6174 CNRS-UFC-ENSMM-UTBM \\ * SENSeOR, TEMIS Innovation \\ Besançon, France \\ sylvain.ballandras@femto-st.fr
}

\begin{abstract}
Surface acoustic wave (SAW) gas sensors generally require the use of a reactive layer for molecule adsorption. $\mathrm{WO}_{3}$ has been identified for a long time as a high potential sensitive layer particularly for $\mathrm{NH}_{3}, \mathrm{NO}_{\mathrm{x}}$, $\mathrm{CO}$, etc. We report here on the characterization of elastic properties of such material using the dispersion behavior of SAW propagating under gratings passivated wich $\mathrm{WO}_{3}$ films of various thicknesses. Quartz as well as $\mathrm{LiNbO}_{3} \mathrm{SAW}$ devices are used in that purpose, allowing for the derivation of a reliable data set. Complementary structural characterization using direct measurement techniques (DRX, AFM, TEM,) are reported to confirm the analysis deduced from SAW measurements. As a conclusion, the exploitation of $\mathrm{WO}_{3}$ for SAW-based sensor is discussed.
\end{abstract}

\section{INTRODUCTION}

Surface Acoustic Wave (SAW) sensors are presently receiving an increasing interest, although many works has been dedicated to operate to such developments. A particular effort is paid to develop devices capable to detect gas flows in common environment for health protection or security purposes. The arising of new materials and technologies actually pushes to re-investigate the capability of such devices to efficiently operate, particularly in harsh environment such as toxic atmospheres and high temperature. Hence, the possibility to remotely interrogate gas sensors based on resonator structures can be actually implemented and tested. In this work, we propose to characterize the operation of SAW resonator sensors coated with tungsten trioxide $\left(\mathrm{WO}_{3}\right)$, a layer which exhibits selective detection capabilities when heated near $350^{\circ} \mathrm{C}$. The exploited principle consists in the change of dielectric properties of the film when adsorbing specific molecules $\left(\mathrm{O}_{3}, \mathrm{NO}_{2}, \mathrm{NH}_{3}\right.$ and ethanol). The design of such sensors requires the knowledge of the actual properties of the detection film as it is directly deposited atop the resonator electrodes, yielding modal dispersion which must be accounted for to guaranty the device operation according given requirements (such as those imposed by wireless interrogation in ISM bands). In that purpose, test devices have been fabricated, based AT Quartz and $(\mathrm{YXl}) / 128^{\circ} \mathrm{LiNbO}_{3}$ synchronous resonators operating near the 434-MHz-centered ISM band, coated with various $\mathrm{WO}_{3}$ thicknesses $(100,200$ and $300 \mathrm{~nm})$. These thins films were characterized using X-ray diffraction/Rietveld refinement and the samples morphology were analyzed by Atomic Force and transmission electron microscopy. The diffract pattern showed the monophasic layers with the same crystallinity and they reveal a pseudo cubic phase (isotropic behaviour). We then have measured the reflection coefficient of the resonators allowing for fitting the coating elastic properties by model updating. This fit has been first achieved using quartz resonators and we have obtained the fitted coefficients (apparent elastic constants $C_{11}, C_{12}, C_{44}$ and mass density $\rho$ ). They have been used to predict the coatinginduced frequency shift on lithium niobate resonators. Although mass density is found to change dramatically versus $\mathrm{WO}_{3}$ thickness (from 6500 to $3900 \mathrm{~kg} \cdot \mathrm{m}^{-3}$ ), the elastic constants reveal more stable $\left(C_{11}\right.$ and $C_{44}$ typically equal to 15,8 and $2.5 \mathrm{GPa}$ respectively). The max coating thickness actually is found near $300 \mathrm{~nm}$, but it turns out that above 200 $\mathrm{nm}$, the resonator response is too degraded to allow for any operation. A specific design then is proposed on $\mathrm{LiNbO}_{3}$ for assessing the actual operation of the sensor.

In the first section of the paper, we report a direct analysis of the deposited material also has been achieved to complement and justify effective data derived using SAW-based measurements. Next, we briefly describe $\mathrm{WO}_{3}$ coating properties, with a particular insight in physical parameter changes related to gas adsorption and the subsequent SAWsensor application. As such devices need accurate design procedure to optimize their actual operation; the characterization of $\mathrm{WO}_{3}$ elastic properties was a prerequisite and therefore the experimental measurements of the corresponding physical coefficients then is reported. 
Finally, exploitation of the corresponding results using $\mathrm{LiNbO}_{3} \mathrm{SAW}$ resonators is discussed.

\section{II. $\mathrm{WO}_{3}$ THIN FILM PROPERTIES FOR GAS DETECTION}

The structural configuration of the $\mathrm{WO}_{3}$ crystal lattice is the distorted rhenium trioxide $\left(\mathrm{ReO}_{3}\right)$ structure [1,2]. The crystal structure of tungsten trioxide is temperature dependent. The most common structure of $\mathrm{WO}_{3}$ is monoclinic $(\mathrm{P} 21 / n)$. Based on the reversible changes in conductivity, $\mathrm{WO}_{3}$ thin films have been used as sensitive layers towards $\mathrm{O}_{3}, \mathrm{NH}_{3}, \mathrm{NO}_{\mathrm{x}}, \mathrm{CO}$, ethanol [3,4]. It was shown that the conductivity of $\mathrm{WO}_{3}$ thin films changed in presence of $\mathrm{NO}_{\mathrm{x}}$ gas with a dependence of temperature. At $375^{\circ} \mathrm{C}$ the resistance of $\mathrm{WO}_{3}$ drop by a factor of 100 compared to its initial value at room temperature from $6.10^{9}$ to $6.10^{7} \mathrm{ohms}$ respectively [5]. This behaviour can be explained by physisorptions and chemisorptions mechanisms and catalytic reactions between gases and material surface (phenomenon of adsorption and desorption) [6]. Due to its electrical properties, $\mathrm{WO}_{3}$ is an ideal candidate for applications SAW gas sensors. Indeed, the interaction between gases molecules and tungsten trioxide causes a change in conductivity of thins films $\mathrm{WO}_{3}$ resulting from in a variation of the velocity and propagation loss of the acoustic wave. By measuring the change in the frequency characteristics of the SAW sensor, it was possible to determinate different physical parameters of the sensitive layer $\mathrm{WO}_{3}$ and sees the influence of the viscoelastic layer on the SAW device (dielectric loss, mass effect) [7,8]. To achieve this, it is imperative to have strong knowledge in the field of piezoelectricity and acoustic.

\section{STRUCTURAL CHARACTERIZATION}

\section{A. Experimental}

$\mathrm{WO}_{3}$ thin films on the surface of a quartz substrate for SAW devices were prepared by reactive radio frequency magnetron sputtering at $13.56 \mathrm{MHz}$, using a $99.9 \%$ pure tungsten target. The synthesis setup and standard procedure have been described in more detail by previous work of the lab [6]. The obtained films were annealed at $400^{\circ} \mathrm{C}$ for 3 hours.

\section{B. Characterization and results}

The morphological analyses of $\mathrm{WO}_{3}$ thin films were conducted by Atomic Force (AFM) and Transmission Microscopy (TEM, Philips TECNAI F20 FEG).

The structure properties of $\mathrm{WO}_{3}$ films were determined by $\mathrm{X}$ ray diffraction with $\mathrm{Cu} . \mathrm{K} \alpha$ radiation (Siemens - Brucker D5000 diffractometer). X-ray patterns were compared with those of the Joint Committee on Powder Diffraction Standards (JCPDS). The DBWS Tools 2.16 software was used to perform Rietveld Refinement. Figure 1.a shown the state surface of the deposited $\mathrm{WO}_{3}$ films on quartz substrates and reveals a weak roughness and a porous surface. This porosity varies from $10 \mathrm{~nm}$ to $100 \mathrm{~nm}$ and they extended in deep layers. The TEM image (fig 1.b) shows a cross section of the oxide layer deposited on $\mathrm{Si}$ substrate reference. For all studied thicknesses of $\mathrm{WO}_{3}: 50,100,200$ and $300 \mathrm{~nm}$, all films were homogenous.
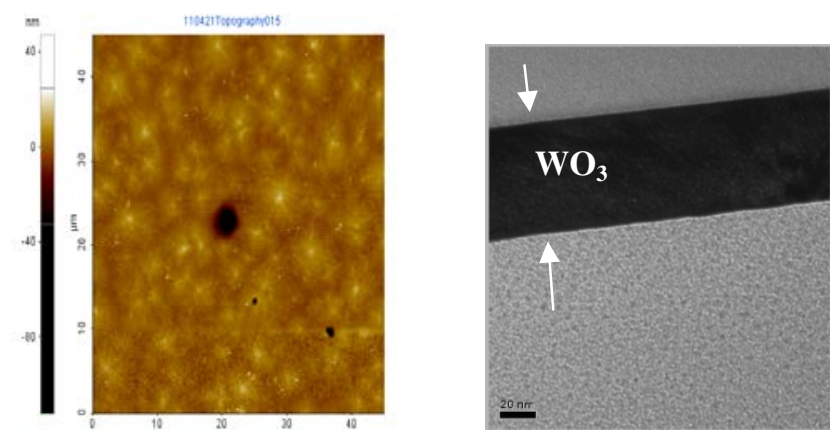

Figure 1. a) AFM image of $\mathrm{WO}_{3}$ films on quartz substrate after annealing at $400^{\circ} \mathrm{C}$ for 3 hours; b) TEM cross section of $\mathrm{WO}_{3}$ thin film thickness of 50 nm on $\mathrm{Si}$ substrate

The X-ray diffraction patterns and Rietveld refinement of trioxide tungsten are in good agreement (figure 2) showing a low crystallite size in accordance with TEM observation.

The XRD diagram show a polycrystalline structure identified as monoclinic phase and indexed from standard data sheet. The observed structural parameters are in good agreement with JCPDS (No. 83-0950) data [9].

From Rietveld refinement results, it is proved that $\mathrm{WO}_{3}$ thin films have a monoclinic phase close to cubic one. The evaluated lattice parameter values of $\mathrm{WO}_{3}$ are $a=7.308 \AA, b$ $=7.514 \AA, c=7.675 \AA, \alpha=\gamma=90^{\circ}$, and $\beta=90,632^{\circ}$. This allows to hypothesize that $\mathrm{WO}_{3}$ films behave as an isotropic system. All deposited layers (50 to $400 \mathrm{~nm}$ ) were structured in the same phase and the calculated parameters remain unchanged.

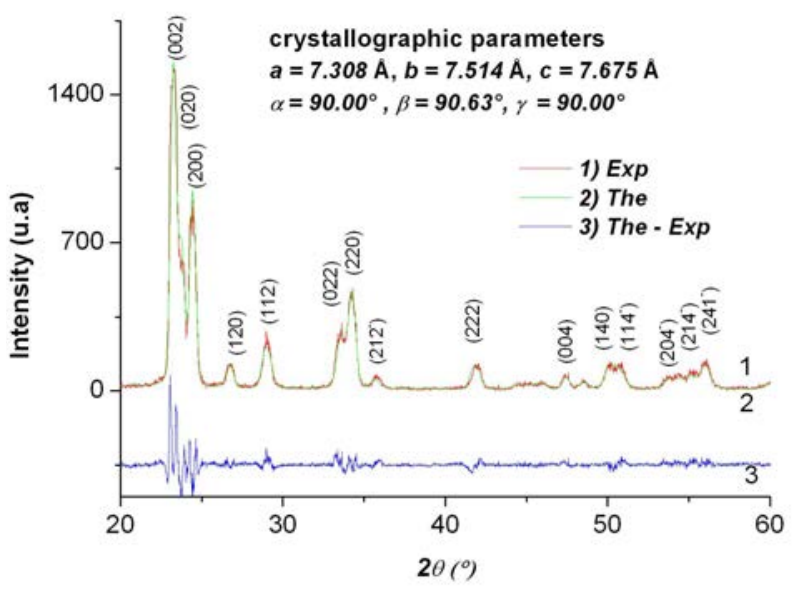

Figure 2. X-ray diffractogram (1.Exp) and theory Rietveld refinement (2.The) of $\mathrm{WO}_{3}$ thin films with a thickness of $50 \mathrm{~nm}$ 


\section{IV. $\mathrm{WO}_{3}$ ELASTIC CONSTANTS CHARACTERIZATION}

In this section, the theoretical and experimental protocols for characterizing the $\mathrm{WO}_{3}$ overlay properties are described, using Quartz SAW resonators (fig.3). The quality of the obtained physical paremeters is the assessed for $\mathrm{LiNbO}_{3}(\mathrm{YZ})$ devices better suited for dielectric perturabtion detections.

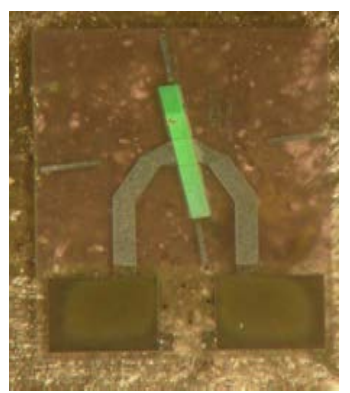

Figure 3. $\mathrm{WO}_{3}$ thin film deposited on SAW devices

\section{A. Theoretical analysis}

As layered devices are concerned, with the $\mathrm{WO}_{3}$ overlay covering the electrodes, one cannot make the economy for advanced simulation and analysis exploiting a combination of finite element and boundary element methods (FEM/BEM) developed in that purpose [10]. We here briefly recall the analysis approach, detailed description of the calculation fundamentals are reported in [11]. An harmonic admittance is derived from FEM computation of a single period of an infinitely long periodic transducer accounting for the inhomogeneous boundary conditions induced by the electrode/passivation surface conditioning. The acoustic contribution of the substrate is accounted for by Green's function based BEM. For an accurate simulation of the device behavior, one need a reliable set of physical constants, i.e. elasticity coefficients, mass density and dielectric parameters and associated intrinsic losses if available. Although some data can be found in the literature, providing a starting point for the simulation, a set of experiments has been achieved on SAW resonators of fig. 1 built on a $(\mathrm{ST}, \mathrm{X}+\psi)$ cut with $\psi$ a small non zero propagation angle, therefore providing clear contributions at both edges of the stop-band and hence a direct evaluation of the reflection coefficient magnitude. This will be used for improving the theory/experiment agreement and consequently the accuracy of the above-mentioned constant determination.

\section{B. Experimental implementation}

As explained above, SAW resonators built on Quartz have been used first to determine the $\mathrm{WO}_{3}$ overlay properties required for sign and analysis purposes. The asynchronous single-port resonators implemented in that purpose consist of one interdigited transducer (IDT) surrounded by two Bragg mirrors. They have been designed to operate at best in the 434-MHz centered ISM band. The IDT is composed of $82 \mathrm{Al}$ electrode pairs with a mechanical period $p$ of $3.627 \mu \mathrm{m}$ and a metallisation ratio $a / p$ of 0.8 to benefit for the reflection coefficient stabilitiy versus electrode width $a$. As suggested above, the mirror period differs from the IDT one, being fixed to $3.646 \mu \mathrm{m}$ (same metallisation ratio) to force the resonance within the stopband of the mirrors and hence increasing their reflecvtion efficiency. The metal height $h$ is $120 \mathrm{~nm}\left(h / \lambda_{a c} \sim 1.5 \%\right)$. The acoustic apperture is $320 \mu \mathrm{m}(40$ $\left.\lambda_{a c}\right)$ to avoid any possible diffraction effect. These devices have been then covered with $\mathrm{WO}_{3}$ overlays of different thicknesses $(50,100,200,300$ and $400 \mathrm{~nm})$ to achieve the characterization discussed in the previous paragraph. Figure 4 shows the corresponding experimental electrical admittances compared with theoretical harmonic admittances derived with FEM/BEM. For each configuration, a set of material constants has been fitted to achieve the maximum agreement between both curves, reported in Table I. As one can easily see, the acoustic dissipation increases along the $\mathrm{WO}_{3}$ thickness in such a way that above a $300 \mathrm{~nm}$ thick deposition, the experimental signal was no more exploitable (fig.5). Also the viscoelastic losses of the overlay has been fitted according to experimental observations, yielding an equivalent mechanical quality factor of 50 whatever was the $\mathrm{WO}_{3}$ thickness.

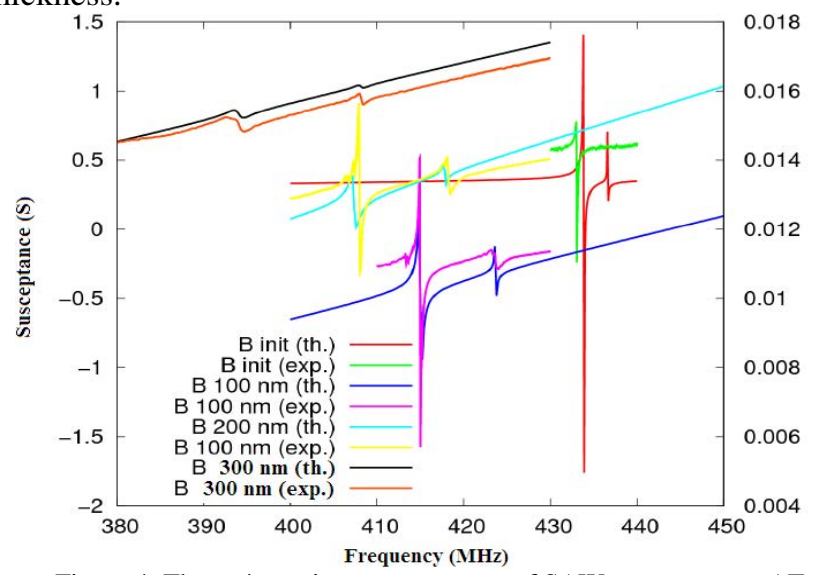

Figure 4. Theory/experiment assessment of SAW resonators on ATQuartz cut for different $\mathrm{WO}_{3}$ overlay thickness

In all the simulations, a relative dielectric constant of 230 has been fixed according to published material [12]. As shown by Table I, the mass density was changed along the $\mathrm{WO}_{3}$ thickness for best fit purposes. Although one could also change the elastic constants in that matter, the reflection coefficient gave helpfull tracks for the fitting strategy, as it strongly depends on the combination of all the elastic constants. One could imagine keeping the mass density unchanged versus $\mathrm{WO}_{3}$ thickness but the ratio between the elastic constants would then be kept unchanged. From a structural point of view, the film is assumed polycristalline and porous. This porosity vary with the deposition thickness. Within each grain, the elasticity behaviour is not changed but the overall of the layer actually reduces along the deposition height. 


\begin{tabular}{|c|c|c|c|c|c|c|}
\hline \multirow{2}{*}{$\begin{array}{l}\text { Materials } \\
\text { Physicals } \\
\text { properties }\end{array}$} & \multicolumn{3}{|c|}{ AT Quartz } & \multicolumn{3}{|c|}{$(\mathrm{YX} l) / 128^{\circ} \mathrm{LiNbO}_{3}$} \\
\hline & $100 \mathrm{~nm}$ & $200 n m$ & $300 n m$ & $100 \mathrm{~nm}$ & $200 \mathrm{~nm}$ & $300 \mathrm{~nm}$ \\
\hline $\begin{array}{c}\text { Density } \rho \\
\left(\mathrm{kg} \cdot \mathrm{m}^{3}\right)\end{array}$ & 6500 & 4700 & 3900 & 6500 & 4700 & 3900 \\
\hline$C_{11}(\mathrm{GPa})$ & 14 & 15 & 12.5 & 14 & 15 & 15 \\
\hline$C_{12}(\mathrm{GPa})$ & 8 & 8 & 7 & 8 & 8 & 8 \\
\hline$C_{44}(\mathrm{GPa})$ & 2.5 & 2.5 & 2.5 & 2.5 & 2.5 & 2.5 \\
\hline
\end{tabular}

Table I .Apparent elastic constants and density of the $\mathrm{WO}_{3}$ versus overlay thickness. The initial value of the density was fixed to $7200 \mathrm{~kg} \cdot \mathrm{m}^{-3}$ according to the literature and adjusted versus thickness for best fit purposes.

\section{Validation on $\mathrm{LiNbO}_{3} \mathrm{SAW}_{\mathrm{W}}$ resonators}

The previous section has shown the way the physical parameters of the $\mathrm{WO}_{3}$ overlay, more specifically the elastic constants and mass density, has been fitted. To confirm the reliability of these data, another set of experiments has been achieved using SAW resonators built on (YZ) $\mathrm{LiNbO}_{3}$ cut with similar $\mathrm{WO}_{3}$ deposition conditions and thickness (fig 3). As for Quartz resonators, a FEM/BEM analysis then was conducted using the fitted parameters to assess the experimental results. Figure 4 shows the corresponding experimental admittances compared with theory. For best fit purposes, slight changes have been applied to the elastic parameters but the overall behaviour of the device responses was well predicted using Quartz-resonator-derived data, yielding confidence in their physical meaning. Particularly, the frequency shift related to mass loading was found in good agreement here again and therefore, the above-proposed hypothesis concerning the porous surface and weak roughness was not infirmed. From a pragmatical point of view, these results show that the fitted apparent elastic constants and mass density can be used for the design of a next generation of sensors. This work is currently under development.

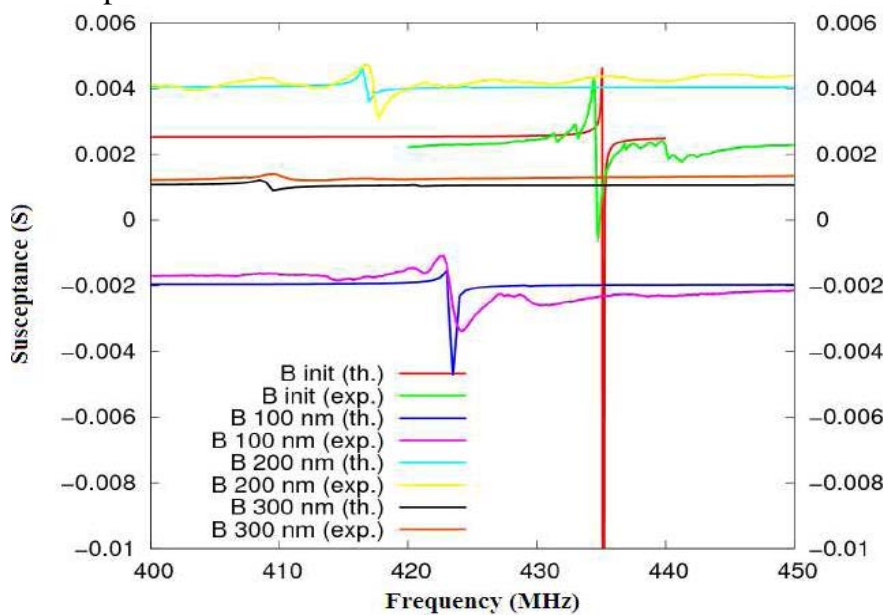

Figure 5. Theory/experiment assessment of SAW resonators on $(\mathrm{YXl}) / 128^{\circ} \mathrm{LiNbO}_{3}$ for same $\mathrm{WO}_{3}$ overlay thickness

\section{CONCLUSION}

In this work, we investigated the design and the physical properties of $\mathrm{WO}_{3}$ using SAW devices as a mean of characterzation. A pseudo cubic as isotropic system was identified for $\mathrm{WO}_{3}$ sensitive films via structurals analysis. The measured reflection coefficient allowed to estimate the elastic properties and induced frequency shift on quartz/lithium niobate resonators as a function of the $\mathrm{WO}_{3}$ layers thickness. Although mass density is found to change as a function of $\mathrm{WO}_{3}$ thickness and their porosity, the apparent elastic constants reveal more stable. The max coating thickness actually is found near $300 \mathrm{~nm}$, but it turns out that above 200 $\mathrm{nm}$, the resonator response is too degraded to allow for any operation.

\section{ACKNOWLEDGMENT}

We gratefully acknowledge the PACA Regional Council, the General Council of Var, and the agglomeration community of Toulon Provence Mediterranean for their financial supports.

\section{References}

[1] P. Cox, "The Electronic Structure and Chemistry of Solids", Oxford University Press, Oxford, 1987.

[2] M.S. Whittingham, in: B.V.R. Chowdari, S. Radharkrishna (Eds.), Proceedings of the International Seminar on Solid State Ionic Devices, World Publishing Co., Singapore, 1988.

[3] M. D. Antonik, J. E. Schneider, et al., "Microstructural effects in WO, gas sensing film", Thin Solid Films, vol. 256 , 1995 , pp. 247-252.

[4] M. Stankova, X. Vilanova, et al, "Influence of the annealing and operating temperatures on the gas-sensing properties of rf sputtered $\mathrm{WO}_{3}$ thin-film sensors" Sensors and Actuators, vol. B 105, 2005, pp. 271-277.

[5] Jong-In Yang, H. Lim, Sang-Do Han, "Influence of binders on the sensing and electrical characteristics of $\mathrm{WO}_{3}$ based gas sensors," Sensors and Actuators vol. B 60, 1999, pp. 71-77.

[6] M. Bendahan, J. Guérin et al., " $\mathrm{WO}_{3}$ sensor response according to operating temperature: Experiment and modelling", Sensors and Actuators, vol.B 124, 2007, pp. 24-29.

[7] S.J. Ippolito, et al., "Layered SAW hydrogen sensor with modified tungsten trioxide selective layer" Sensors and Actuators, vol.B 108, 2005, pp. $553-557$

[8] A.Z. Sadek, "A polyaniline/ $\mathrm{WO}_{3}$ nanofiber composite-based $\mathrm{ZnO} / 64 \circ \mathrm{YX}$ $\mathrm{LiNbO}_{3}$ SAW hydrogen gas sensor", Synthetic Metals, vol.158, 2008, pp.29-32

[9] L. Lozzi, L. Ottaviano, M. Passacantando, S. Santucci, C. Cantalini, Thin Solid Films 391, 2001,pp.224

[10] S. Ballandras, A. Reinhardt,et al, "Simulations of surface acoustic wave devices built on stratified media using a mixed finite element/boundary element integral formulation", Journal of Applied Physics, vol. 96, $\mathrm{N}^{\circ} 12$, 2004, pp.7731-7741.

[11] S. Ballandras, A. Reinhardt,et al, "Theoretical analysis of damping effects of guided elastic waves at solid/fluid interfaces", Journal of Applied Physics, vol. 99, 2006, pp.054907:1-9.

[12] Salje E, "Lattice dynamics of $\mathrm{WO}_{3}$ ". Acta Crystallographica Section A, 1975, 31:360. 